\title{
Real Options Valuation in Gold Mining Projects under Multinomial Tree Approach
}

\author{
Carlos Andres Zapata Quimbayo \\ Universidad Externado de Colombia, Colombia \\ carlosa.zapata@uexternado.edu.co \\ Carlos Armando Mejía Vega \\ Universidad Externado de Colombia, Colombia
}

Received: July 15, 2019 Accepted: August 2, 2019 Published: August 31, 2019

doi:10.5296/ber.v9i3.15096

URL: https://doi.org/10.5296/ber.v9i3.15096

\begin{abstract}
Metal price, exchange rate, and operating costs are three of the most important sources of uncertainty in mining projects. In that sense, numerous research studies have been carried out to account for price uncertainty, while few others have incorporated the simultaneous effects of operating costs and price uncertainties. The purpose of this paper is to introduce the octanomial tree method to value an Australian gold mine project by adding three market uncertainties such as the gold spot price, USD/AUD exchange rate and the operative costs, under a multinomial tree approach. The proposed model combines the simplicity of the binomial tree model with the ability to deal efficiently with multiple uncertainties.
\end{abstract}

Keywords: Real options, octanomial tree, mining projects

\section{Introduction}

Recent studies had shown that is often inappropriate to determine the value of a project through the traditional discounted cash flow (DCF) method (Trigeorgis, 1996; Copeland and Antikarov, 2001) since it does not include its operational flexibilities and future uncertainties. As a result, by the adaptation of the financial option pricing models, developed by Black and Scholes (1973) and Merton (1973), the real options approach (ROA) appeared as a useful tool for making optimal investment decisions that incorporate the value of both flexibilities and uncertainty. Therefore, investment projects could be valuated by introducing continuous-time stochastic models like the geometric Brownian motion (GBM), or its adaptation in discrete time, under the numerical methods framework known as the binomial model developed by 
Cox, Ross and Rubinstein (1979).

Furthermore, talking specifically about natural resources investments, e.g., mining projects, some works had also shown that the ROA approach constitutes a better tool for assessing investment projects under uncertain market and operational conditions, which characterizes these projects, compared to DCF methods, such as the net present value (NPV). Some relevant works in that sense are the ones of Brennan and Schwartz (1985), Dixit and Pindyck (1994), Costa-Lima and Suslick (2006) and Haque Topal and Lilford (2014). Therefore, the ROA approach has found numerous applications in the valuation of the mining projects, when it is necessary an appropriate treatment of several uncertainties.

Brennan and Schwartz (1985) were the ones that developed, for the first time, a stochastic model to value mining projects, specifically a copper mine, where they assumed that the commodity price follows a GBM. Furthermore, they extended this approach by introducing stochastic control theory to find optimal exercise policies. Since then, several authors have developed different applications in the mining industry under the ROA. Some relevant works in that sense are the ones of Paddock, Siegel and Smith (1988); Dixit and Pindyck (1994); Kelly (1998); Smith and McCardle (1999); Brennan and Trigeorgis (2000); Topal (2008) and Miranda and Brandão (2013).

Although these works have successfully implemented the ROA for this type of projects, most of these studies are limited. Mining projects are not only affected by the commodity price uncertainty, but also by other factors such as operational costs (Pindyck, 1993) or foreign exchange rates (Dixit, 1989; Dimitrakopoulos and Abdel-Sabour, 2007; Haque et al. 2014). Additionally, the treatment to deal with more than one uncertainty at the time is much more complicated than the simple model assumed in most of the current literature (Gamba and Trigeorgis, 2007). When the project includes only one source of uncertainty - e.g., commodity price, this risk can be modeled by using widely-known techniques for valuing real options such as binomial lattice methods. However, in projects that are affected by several uncertainties, the valuation technique should be improved like Smith and Nau (1995) suggested.

Following that guideline, more robust real option valuation techniques have been developed by Clewlow and Strickland (1998) and Gamba and Trigeorgis (2007) under a multidimensional approach with correlated geometric Brownian processes. Previous developments inspired these seminal papers, especially, the ones of Boyle (1988), Boyle, Evnine and Gibbs (1989), Kamrad and Ritchken (1991) and Herath and Kumar (2006). Specifically, Kamrad and Ritchken (1991) proposed a model (KR model) for valuing contingent claims with many state variables. The proposed model extended previous works based on this approach as the ones of Boyle (1988), and Boyle et al. (1989) by allowing for horizontal jumps. However, their model has several limitations, as Herath and Kumar (2006) suggested it. The KR model ignores higher-order terms of time step in the approximation process when they calculate the jump probabilities and the stretch parameter " $\lambda$ ", which is required to obtain a possible set of probabilities, is chosen arbitrarily. In that sense, Herath and Kumar (2006) modified the KR model (named MKR model) by including an omitted 
second-order term that allows them to derive analytical bounds. In this way, they reduce errors and ensure that probabilities are non-negative.

Under these different frameworks, Dehghani, Ataee-pour and Esfahanipour (2014) developed a novel valuation method named pyramid technique based on the multidimensional binomial tree method as an extension of Clewlow and Strickland (1998) model. Under this model, the authors evaluated a copper mine with two simultaneous stochastic processes, metal prices and operating costs. They concluded that under this method, the mine valuation model produces a more suitable NPV. However, it is still necessary to include a third source of uncertainty for mining projects (e.g., exchange rate), and to bring it together with commodity prices and operative costs under a complete ROA framework.

Additionally, under the framework of multidimensional models, some recent applications are the ones of Song et al. (2017), Xiao and Zhou (2017), Hillman, Zhang and Jin (2018). Song et al. (2017) employed an irreversible regime-switching Markov chain model for the multi-stage and technology life cycle of the project in the high-tech industry, where they implemented a multinomial lattice-based method to value a project like an American option with a time-dependent strike price.

Xiao and Zhou (2017) used a multinomial pricing model to value a mining concession of a copper mine in China. In this case, they assume that the annualized volatility of the mineral spot price is the one that follows a multinomial distribution. Additionally, they show that this model provides a more comprehensive consideration of the changing annualized volatility than the traditional decision tree methods. Finally, Hillman et al. (2018) extended previous works to value a real option. To do that, they include two separate effects: i) the possibility that the project value is partly describable according to a jump-diffusion process, and, ii) the incorporation of a time-dependent investor utility function by considering the effect of inflation.

Based on this, the purpose of this paper is to introduce the octanomial tree method to value an Australian gold mine project by adding three market uncertainties such as the gold spot price, USD/AUD exchange rate and the operational costs, under a multidimensional binomial tree approach. This paper is organized as follows. In section 2, a general overview of both the binomial and multidimensional models are presented. In section 3 , the hypothetical case study of the Australian gold mine is presented. In section 4, the real option model is introduced, and finally, section 5 presents the conclusions.

\section{Valuation Lattice Models}

\subsection{The Binomial Model}

The binomial model, developed by Cox et al. (1979) (CRR approach) as an alternative to the Black and Scholes (1973) model and the Merton (1973) model, assumes that the price of the underlying asset $\left(S_{t}\right)$ under a defined the probability space $\left[\Omega, \mathcal{F}\left(\mathcal{F}_{t \geq 0}\right), P\right]$ follows a multiplicative binomial process over discrete periods with $\Delta t$ length and $\Omega=\left(\omega_{1}, \omega_{2}\right)$. Given this framework and considering only one period ahead, it is possible to to define $S_{0}$ as the price in $t=0$ and $S_{1}$ as the price at the end of the period $(t=1)$. Now, if $S_{1}^{u}$ and $S_{1}^{d}$ 
are the two possible prices in the future, the model considers them as the result of multiplying $S_{0}$ by an up-factor $u$ or a down-factor $d$ - i.e. $S_{1}^{u}=u S_{0}$ and $S_{1}^{d}=d S_{0}$. The probabilities of going up or of going down, $p$ and $1-p$, respectively, should be expressed under the risk-neutral framework. In that sense, under a risk-neutral valuation approach, it is necessary that $0<d<e^{r \Delta t}<u$, where $r$ is the risk-free interest rate.

The volatility of the underlying asset $(\sigma)$ is essential to estimate the factors $u$ and $d$, which are given by $u=\exp (\sigma \sqrt{\Delta t})$ and $d=\exp (-\sigma \sqrt{\Delta t})$, as well as the probabilities $p$ and $1-p$ which are specified by:

$$
p=\frac{e^{r \Delta t}-d}{u-d} \quad \text { and } 1-p=\frac{u-e^{r \Delta t}}{u-d}
$$

where $\Delta t=1$ is the time step. Now, by introducing an option call with current value $C$, it is possible to define $C_{u}$ as its value at the end of the period if the underlying price goes up $\left(u S_{0}\right)$ and $C_{d}$ as the value if the underlying price goes down $\left(d S_{0}\right)$. Following Cox et al. (1979), a rational exercise policy imply that $C_{u}=\max \left[u S_{0}-K, 0\right]$ and $C_{d}=\max \left[d S_{0}-\right.$ $K, 0]$. Figure 1 shows this relation.
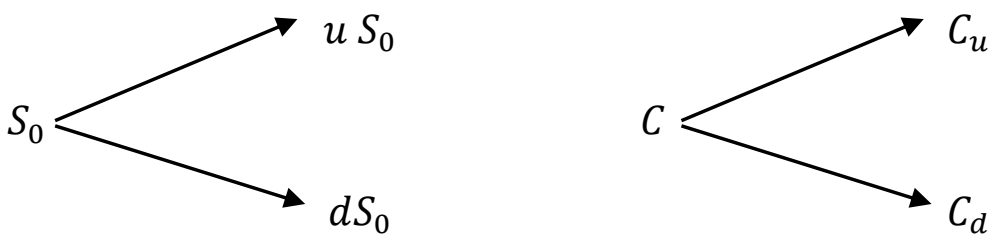

Figure 1. Binomial Tree

This binomial model can be extended to multiple periods to represent the dynamics of the underlying asset. The advantage of this implementation is its numerical ability to find the value of an option, not only for European style options, but also for the more complex structures of American options (Copeland and Tufano, 2004) ${ }^{1}$. Given this framework and under the ROA, the value of a project can be modeled as a stochastic process through a discrete recombinant binomial lattice, following Cox et al. (1979).

\subsection{The Multinomial Model}

The Binomial model is based on lattices with two possible movements, either up or down, and both movements can be described as the different states of the world. Thus, throughout the CRR approach, the binomial tree can represent the dynamics of the present value of the futures free cash flows along the project life, and so it allows to value its flexibilities (Trigeorgis, 1996; Copeland and Antikarov, 2001). However, the CRR approach has some limitations, like Kamrad and Ritchken (1991) suggested. For instance, if the goal is to obtain the value of a project with many uncertainties simultaneously, the model cannot be applied. For example, mining projects can be affected by many uncertainties like commodity prices

\footnotetext{
${ }^{1}$ Copeland and Tufano (2004) state that the binomial model allows to effectively capture the complexity and the iterative character of managerial decisions and their contingencies. In that sense, the model shows a practical alternative to solve the fundamental problem in the valuation of the real options compare with the Black-Sholes-Merton model.
} 
(Brennan and Schwartz, 1985; Paddock et al., 1988; Cortazar and Schwartz, 1993; Kelly, 1998), operational costs (Pindyck, 1993) or foreign exchange rates (Dixit, 1989; Dimitrakopoulos and Abdel-Sabour, 2007; Haque et al., 2014). Therefore, the valuation methods should be improved to make correct investment decisions, leading to the development of the multinomial lattice models.

Based on the pricing options theory, there are different models to value financial options with multiple underlying sources. The first is the one of Boyle, Evnine, and Gibbs (1989), where they considered an alternative approximating procedure (known as BEG model) following the work of Boyle (1988). Specifically, Boyle (1988) used a trinomial lattice where the first two moments of the discrete process are equated with the ones of the underlying process to obtain the jump probabilities. However, even he introduced a stretch parameter $(\lambda)$, which must be constrained with values of $\lambda \geq 1$, he did not provide ways to select a suitable parameter. In that sense, Boyle et al. (1989) generalized this approach for $k$-state variables where they used a 4-jump multi-period lattice.

Later, Kamrad and Ritchken (1991) proposed a multidimensional model (known as the KR model) as an extension of the one introduced by Boyle et al. (1989). They show that when $\lambda=1$, the binomial model is a special case of their one state model, while the BEG model is a special case of their two-state model. However, their initiative has several limitations. According to Herath and Kumar (2006), the KR model ignores higher-order terms of time step in the approximation process when they calculate the jump probabilities, and so negative probabilities can occur when $\lambda \geq 1$. Thereby, Herath and Kumar (2006) use new expressions to obtain positive probabilities by defining bounds for the stretch parameter.

Based on what was stated before and, by following the work of Herath and Kumar (2006), this paper applies an extension of the binomial lattice approach with multinomial correlated geometric Brownian processes. Under this second method, there are now $k$ sources of uncertainty. Each one will follow a GBM such that:

$$
d S_{i}(t)=\mu_{i} S_{i}(t) d t+\sigma_{i} S_{i}(t) d W_{i}(t) ; i=1, \ldots, k
$$

where $S_{i}$ represents the $i$-th source of uncertainty, $\mu_{i}$ and $\sigma_{i}$ are the instantaneous trend terms of the total returns and the volatilities, respectively, of each $i$-th stochastic process, and $d W_{i}$ is the standard Wiener process for each case. Furthermore, we assume that the pairwise correlation between the $i$-th and $j$-th uncertainties are $\rho_{i, j}$ so that:

$$
d W_{i}(t) d W_{j}(t)=\rho_{i, j} d t
$$

By considering three sources of uncertainty, as is the case in this paper, it is possible to construct an octanomial tree. This structure is a three-variable binomial tree and is a straightforward generalization of the CRR approach. There are eight branches instead of two (binomial) or four (quadranomial) at every node, corresponding to eight possible combinations of the spot price, exchange rate and operative costs going up $\left(u_{i}\right)$ or down $\left(d_{i}\right)$. Furthermore, each uncertainty is assumed to follow a GBM in a multidimensional context.

Figure 2 illustrates the eight outcomes that are possible, at the end of period $t=1$, if the 
value of the project in $t=0$ is $V_{0}$.

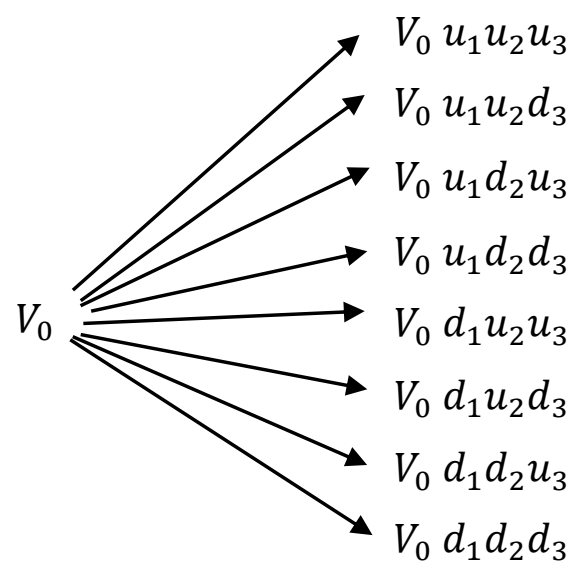

Figure 2. Octanomial tree

To develop the tree, it is necessary to estimate the state probabilities by taking the annual volatility term of the three uncertainties $\sigma_{1}, \sigma_{2}$ and $\sigma_{3}$, as well as the correlation between them, $\rho_{12}, \rho_{13}$ and $\rho_{23}$. Based on this, the total number of jump probabilities in the model are $2^{k}+1$ such that $\sum_{m=1}^{2^{k}+1} p_{m}=1$. By allowing equal up and down jump sizes it is possible to compute the probabilities, where the expected values and variances of the discrete risk-neutral processes are matched with the ones of the underlying sources of uncertainty. Following Herath and Kumar (2006), the probabilities are given by equation (3)

$$
\begin{gathered}
p_{m}=\frac{1}{2^{k}}\left[\frac{1+\vartheta_{1}^{2} \Delta t}{\lambda_{1}^{2}}+\sqrt{\Delta t} \sum_{i=1}^{k} x_{i m}\left(\frac{\vartheta_{i}}{\lambda_{i}}\right)+\sum_{i=1}^{k-1} \sum_{j=i+1}^{k} x_{i j}^{m}\left(\frac{\rho_{i, j}+\vartheta_{i} \vartheta_{j} \Delta t}{\lambda_{i} \lambda_{j}}\right)\right] \\
m=1,2, \ldots, 2^{k} ; k=3
\end{gathered}
$$

with:

$x_{i m}=\left\{\begin{array}{c}+ \text { shows the uncertainty factor } i \text { has an up jump at time } t \\ - \text { shows the uncertainty factor } i \text { has a down jump at time } t\end{array}\right\}$

$x_{i j}^{m}=\left\{\begin{array}{c}+ \text { if uncertainties } i \text { and } j \text { have jumps in the same direction } \\ - \text { if uncertainties } i \text { and } j \text { have jumps in the opposite direction }\end{array}\right\}$

and, the probability expression for the horizontal jump, $p_{2^{k}+1}$ is

$$
p_{2^{k}+1}=1-\left(\frac{1+\vartheta_{1}^{2} \Delta t}{\lambda_{1}^{2}}\right)
$$

and,

$$
\lambda_{i}=\sqrt{1+\vartheta_{1}^{2} \Delta t}
$$

Thus, all the possible scenarios for changes in the three sources of uncertainties are shown in 
Table 1.

Table 1. Changes in the sources of uncertainties

\begin{tabular}{|l|c|c|c|}
\hline & Commodity Price & Exchange rate & Operative Cost \\
\hline$p_{u u u}$ & + & + & + \\
\hline$p_{u u d}$ & + & + & - \\
\hline$p_{u d u}$ & + & - & + \\
\hline$p_{u d d}$ & + & - & - \\
\hline$p_{d u u}$ & - & + & + \\
\hline$p_{d u d}$ & - & + & - \\
\hline$p_{d d u}$ & - & - & + \\
\hline$p_{d d d}$ & - & - & - \\
\hline
\end{tabular}

And, under this framework, the probabilities are estimated using equation (3).

\section{Application: A Gold Mine Project Valuation}

In this paper, a multidimensional model is implemented to value the investment decision in a hypothetical gold mining project. We have considered three simultaneous stochastic processes to model the dynamics of the gold spot price, operative costs, and exchange rate (USD/AUD) movements along the time. Both the proposed method under ROA with a closure option and the conventional NPV method will be applied to make the investment decision.

\subsection{Hypothetical Case of a Gold Mine}

\subsubsection{Project Overview and Assumptions}

This study is based on a hypothetical case of a gold mine project in Australia (AUS) (Gold Mine). The mine is located in the Goldfields-Esperance region of Western Australia. The total investment expected is $\$ 97.5$ million and take one year. The gold mine is an exploration-stage mine containing approximately a total of 5.4 million tons of ore and 450.000 ounces (oz) of recoverable gold. The ore will be mined in conventional open pits at an average rate of 900.000 tons per year (ton/yr) over a mine life of approximately six years, starting in 2019 after a one-year construction period ${ }^{2}$. Table 2 shows the assumptions of the gold mine production.

Table 2. Assumptions of the gold mine production

\begin{tabular}{|l|c|}
\hline Mine life & $6 \mathrm{yrs}$ \\
\hline Total reserve & $450.000 \mathrm{oz}$ \\
\hline Average grade (g/ton) & 2.0 \\
\hline Mill recovery (\%) & 95 \\
\hline
\end{tabular}

\footnotetext{
2 The project considers a fixed-price contract that included schedule, performance, and completion guarantees. Under the contract, the contractor should provide engineering, procurement, construction (EPC) and preoperational testing for gold processing facilities, including: crushers, conveyors, agglomeration facilities, the leach pad, the ponds and pumping system, carbon columns, the refinery, utilities, and ancillary buildings.
} 
To calculate the total gold recovered of the mine, the ore reserves should be multiplied by the estimated grade of the ore, which estimates the amount of gold present in the ore body, and the mill recovery rate. The parameters of the financial model are presented in Table 3.

Table 3. Financial Parameters

\begin{tabular}{|l|c|}
\hline Average Gold Price (USD/g) & $\$ 42.33$ \\
\hline Average Exchange Rate (AUD/USD) & 0.8 \\
\hline Mine Operating Cost (\$/t) & $\$ 28.22$ \\
\hline Royalties (\% Net Smelter Return) & 5 \\
\hline Risk-adjusted Discount Rate (\%) & 15 \\
\hline Risk-free Rate (\%) & 2.57 \\
\hline Inflation (\%) & 3 \\
\hline Corporate Tax Rate (\%) & 30 \\
\hline
\end{tabular}

Australian Dollar (AUD) will be the currency used to express all the data, including the mine value, with and without flexibility, and the value of the real option. On the other side, the United States Dollar is the currency used to express the gold spot price, but it will be converted into AUD and expressed as AUD/g by using the exchange rate AUD/USD. It is important to highlight that in this hypothetical case, the operative cost cannot be directly observed, so its parameters are estimated using the historical data of the producer price index in the mining industry.

\subsubsection{The Static DCF Analysis: Cash Flows and Firm's Initial Value}

To analyze the feasibility of the gold mine project from a financial point of view, the fundamental variables in a deterministic framework are forecasted, i.e., it is considered that the total production of the mine, the gold spot price, operating costs, and exchange rate are known with certainty (Table 3). With that estimation, the free cash flows for the following six year are shown in Table 4.

Table 4. Free Cash Flow model (\$ 000)

\begin{tabular}{|l|c|c|c|c|c|c|c|}
\hline \multicolumn{1}{|c|}{ Year } & $\mathbf{0}$ & $\mathbf{1}$ & $\mathbf{2}$ & $\mathbf{3}$ & $\mathbf{4}$ & $\mathbf{5}$ & $\mathbf{6}$ \\
\hline Gold recovered (000' oz) & & 1710 & 1710 & 1710 & 1710 & 1710 & 1710 \\
\hline Gross income & & 58 & 63 & 68 & 74 & 80 & 86 \\
\hline Operating Cost & & 25 & 26 & 26 & 27 & 27 & 28 \\
\hline Depreciation & & 16 & 16 & 16 & 16 & 16 & 16 \\
\hline Corporate Tax & & 8 & 10 & 11 & 12 & 14 & 16 \\
\hline Total Capex & 98 & & & & & & \\
\hline Free Cash Flow & $\mathbf{- 9 8}$ & $\mathbf{3 6}$ & $\mathbf{3 9}$ & $\mathbf{4 2}$ & $\mathbf{4 5}$ & $\mathbf{4 9}$ & $\mathbf{5 3}$ \\
\hline Cum. Cash Flow & $\mathbf{- 9 8}$ & $\mathbf{- 6 2}$ & $\mathbf{- 2 3}$ & $\mathbf{1 9}$ & $\mathbf{6 4}$ & $\mathbf{1 1 3}$ & $\mathbf{1 6 7}$ \\
\hline
\end{tabular}

Once the financial model has been built, the expected cash flows are discounted by using a risk-adjusted rate $(15 \%)$, which reflects the financial structure of the project as well as the perceived risks, to obtain the NPV. Therefore, the DCF analysis provides a NPV of $\$ 63.87$ million, an internal rate of return (IRR) of $35 \%$, and a present value (PV) of the futures free 
cash flows $\$ 161.4$ million. These results suggest that the project is feasible (financially viable) since the $N P V>0$ and the $I R R>$ discount rate. However, the model's results depend on the forecast assumptions of critical variables as the gold price, operative costs, and exchange rate. To improve the valuation model, the market uncertainties should be incorporated using the multidimensional approach under ROA by generating multiple paths of the uncertainties and the project's value.

\section{Stochastic Analysis of Uncertainties}

The ROA arose as a response to the limitations of the traditional DCF model used to value projects in a dynamic environment. Since the ROA adapts the financial options pricing models developed by Black and Scholes (1973) and Merton (1973), it can incorporate the value of flexibility and uncertainty into investment decision-making with the purpose of valuing investment projects.

Under a filtered probability space $\left[\Omega, \mathcal{F}\left(\mathcal{F}_{t \geq 0}\right), P\right]$ each of the three variables mentioned before, gold spot price $\left(S_{G}\right)$, USD/AUD exchange rate $\left(S_{E R}\right)$ and operative costs $\left(S_{C}\right)$, will follow each one a GBM. Therefore, by defining $X_{G}(t)=\operatorname{Ln}\left[S_{G}(t)\right], X_{E R}(t)=\operatorname{Ln}\left[S_{E R}(t)\right]$ and $X_{F}(t)=\operatorname{Ln}\left[S_{C}(t)\right]$, and applying Itô's lemma the stochastic processes are the following:

$$
\begin{gathered}
d X_{G}(t)=\left(\mu_{G}-\delta-\frac{\sigma_{G}{ }^{2}}{2}\right) d t+\sigma_{G} d W_{G}(t) \\
d X_{E R}(t)=\left(\mu_{E R}-\frac{\sigma_{E R}{ }^{2}}{2}\right) d t+\sigma_{E R} d W_{E R}(t) \\
d X_{C}(t)=\left(\mu_{c}-\frac{\sigma_{C}{ }^{2}}{2}\right) d t+\sigma_{C} d W_{C}(t)
\end{gathered}
$$

where $\mu_{G}$ represents the instantaneous total trend term of the return of the gold spot price and $\delta$ the constant net spot instantaneous convenience yield. On the other side, $\mu_{E R}$ and $\mu_{c}$ are the instantaneous trend terms of the total returns of both the USD/AUD exchange rate and the operative costs. Furthermore, $\sigma_{G}, \sigma_{E R}$ and $\sigma_{C}$ are the respectively volatilities, meanwhile $d W(t)$ in each case is the increment of a Wiener process. The three processes are correlated: $d W_{G}(t) d W_{E R}(t)=\rho_{G, E R} d t, d W_{E R}(t) d W_{C}(t)=\rho_{E R, C} d t$ and $d W_{G}(t) d W_{C}(t)=$ $\rho_{G, C} d t$.

Additionally, the whole processes are discretized using Euler-Maruyama method in the following way

$$
X_{t}=c+X_{t-1}+e_{t}
$$

where:

$$
X=\left[\begin{array}{c}
X_{G} \\
X_{E R} \\
X_{C}
\end{array}\right] \quad \text { and } \quad c=\left[\begin{array}{c}
\hat{\mu}_{G} \\
\hat{\mu}_{E R} \\
\hat{\mu}_{C}
\end{array}\right]
$$

and, 


$$
\begin{gathered}
\hat{\mu}_{G}=\left(\mu_{G}-\delta-\frac{\sigma_{G}{ }^{2}}{2}\right) \Delta t \\
\hat{\mu}_{E R}=\left(\mu_{E R}-\frac{\sigma_{E R}{ }^{2}}{2}\right) \Delta t \\
\hat{\mu}_{C}=\left(\mu_{C}-\frac{\sigma_{C}{ }^{2}}{2}\right) \Delta t
\end{gathered}
$$

Furthermore, $e_{t}$ is a set of serially uncorrelated disturbances driven by a multivariate normal distribution with expected value $E\left[e_{t}\right]=\mathbf{0}$, and

$$
\operatorname{Cov}\left(e_{t}\right)=\left[\begin{array}{ccc}
\sigma_{G}{ }^{2} \Delta t & \rho_{G, E R} \sigma_{G} \sigma_{E R} \Delta t & \rho_{G, C} \sigma_{G} \sigma_{C} \Delta t \\
\rho_{G, E R} \sigma_{G} \sigma_{E R} \Delta t & \sigma_{E R}{ }^{2} \Delta t & \rho_{E R, C} \sigma_{E R} \sigma_{C} \Delta t \\
\rho_{G, C} \sigma_{G} \sigma_{C} \Delta t & \rho_{E R, C} \sigma_{E R} \sigma_{C} \Delta t & \sigma_{C}{ }^{2} \Delta t
\end{array}\right]
$$

The parameters associated with the gold spot price and the USD/AUD exchange rate are obtained by using quarterly information from March 1990 to September 2017. However, given the fact that there is not historical information of operative costs, the increment of this last variable is approximated with the logarithm change of the producer price index (IPP) of Australia for the coal mining industry. Figure 3 shows the three series.

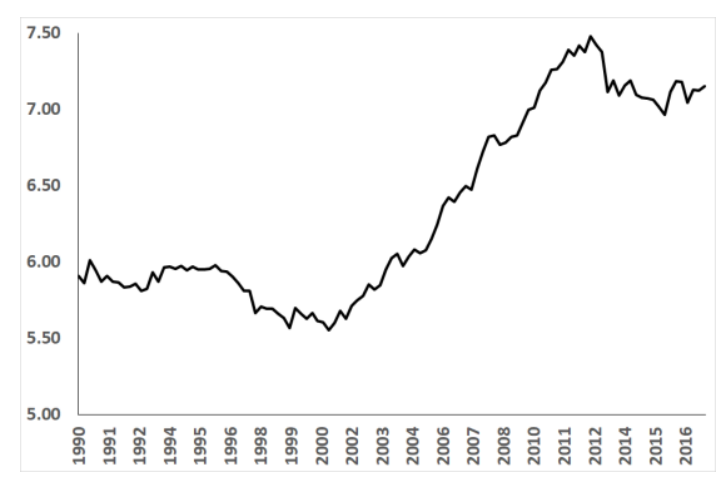

(a) Gold price (USD/oz).

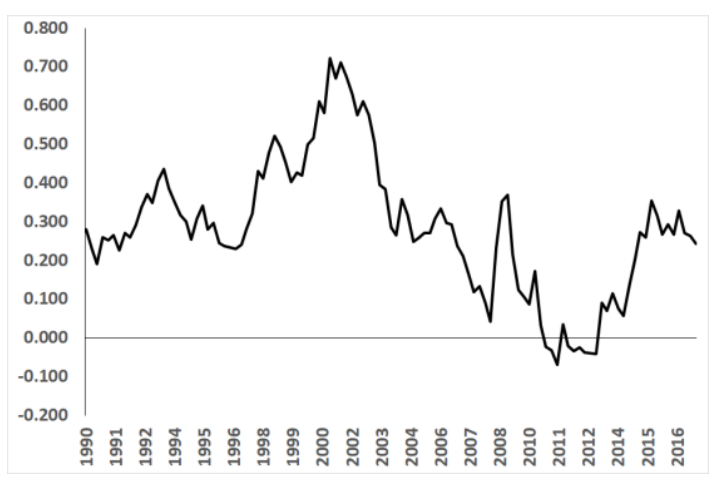

(b) Exchange Rate (AUD/USD).

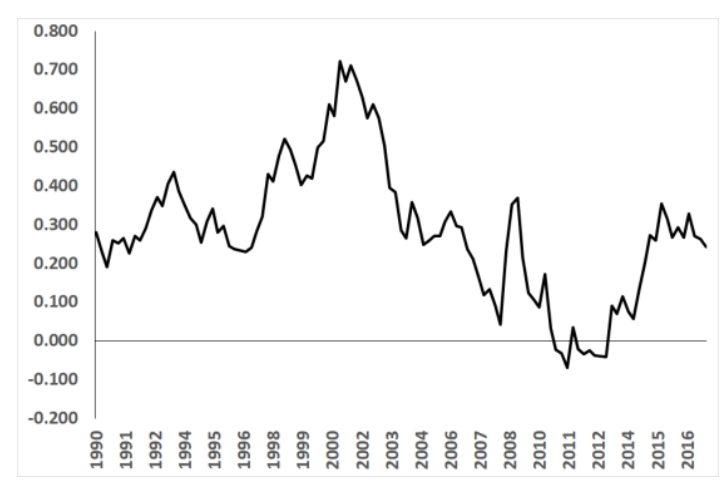

(c) Producer Price Index (IPP).

Figure 3. Historical data for three variables

Additionally, the 10-year Australian bond is used for the estimation of the risk-free rate 
$(2.57 \%)$. On the other side, the net spot instantaneous convenience yield is obtained by following Gibson and Schwartz (1990) estimated in 3.07\%. Table 5 shows the estimated parameters by applying the maximum Log-likelihood method (the $\hat{\mu}_{i}$ were obtained as well as the $\sigma_{i}$ and the $\rho_{i, j}$ first, and then by using $\hat{\mu}_{i}$ and $\sigma_{i}$, the $\mu_{i}$ were finally derived).

Table 5. Fundamental data for Octanomial Tree

\begin{tabular}{|l|c|c|c|}
\hline \multicolumn{1}{|c|}{ Input data } & $\boldsymbol{\mu}_{\boldsymbol{i}}$ & $\boldsymbol{\sigma}_{\boldsymbol{i}}$ & $\boldsymbol{\lambda}_{\boldsymbol{i}}$ \\
\hline Gold spot price & $7.77 \%$ & $16.21 \%$ & 1.022 \\
\hline USD/AUD exchange rate & $0.53 \%$ & $12.08 \%$ & 1.000 \\
\hline Operative cost & $1.75 \%$ & $4.51 \%$ & 1.065 \\
\hline \multicolumn{1}{|c|}{ Correlations } & $\boldsymbol{\rho}_{\boldsymbol{i}, \boldsymbol{j}}$ & & \\
& -0.37 & & \\
\hline Gold spot price / ASD/AUD & 0.09 & & \\
\hline Gold spot price / Operative cost & -0.24 & & \\
\hline Operative cost / ASD/AUD & \multicolumn{2}{|l}{} \\
\hline
\end{tabular}

All the parameters of the Table 5 show the annual estimations - i.e. the instantaneous trend term of the return $\left(\mu_{i}\right)$ and the annual volatility $\left(\sigma_{i}\right)$, from each one of the processes by using the historical series as was indicated before. Additionally, the stretch parameters $\left(\lambda_{i}\right)$ were estimated following Herath and Kumar (2006) as indicated in equation (4b).

\section{Real Options Model for a Gold Mining Project}

If one of the sources of uncertainty has a significant impact on the value of the options compared to the others, or if the management decisions are tied to a particular source of uncertainty, you may want to keep factors separate in the option calculations. Furthermore, when multiple sources of uncertainty are considered simultaneously, the options are known as rainbow options ${ }^{3}$. Real rainbow options have an essential role in natural resources investments, such as mining applications, since there are several uncertainty sources. Based on that, a rainbow option is considered in this case with a payoff $\max \left(V_{t}-I, 0\right)$, and following Copeland and Antikarov (2001), the solution method is basically the same as for a single factor except that it involves an octanomial tree instead of a binomial or quadranomial tree.

\subsection{Option Valuation Using Octanomial Tree}

To obtain the value of the option, an octanomial tree model is built which considers the three correlated uncertainties. The multiplicative movements of the PV of the project for the two periods (year 1 and year 2) are presented in figure 4. The octanomial model is a recombining tree like the binomial tree given that the correlations and volatilities are assumed to be constant. Additionally, Table 6 shows the eight state probabilities according to equation (3).

\footnotetext{
${ }^{3}$ A rainbow option is an option whose payoff depends on multiple sources of different underlying risk assets.
} 


\section{MInstitute ${ }_{\text {Mnit }}^{\text {Macrothin }}$}

Table 6. Probabilities

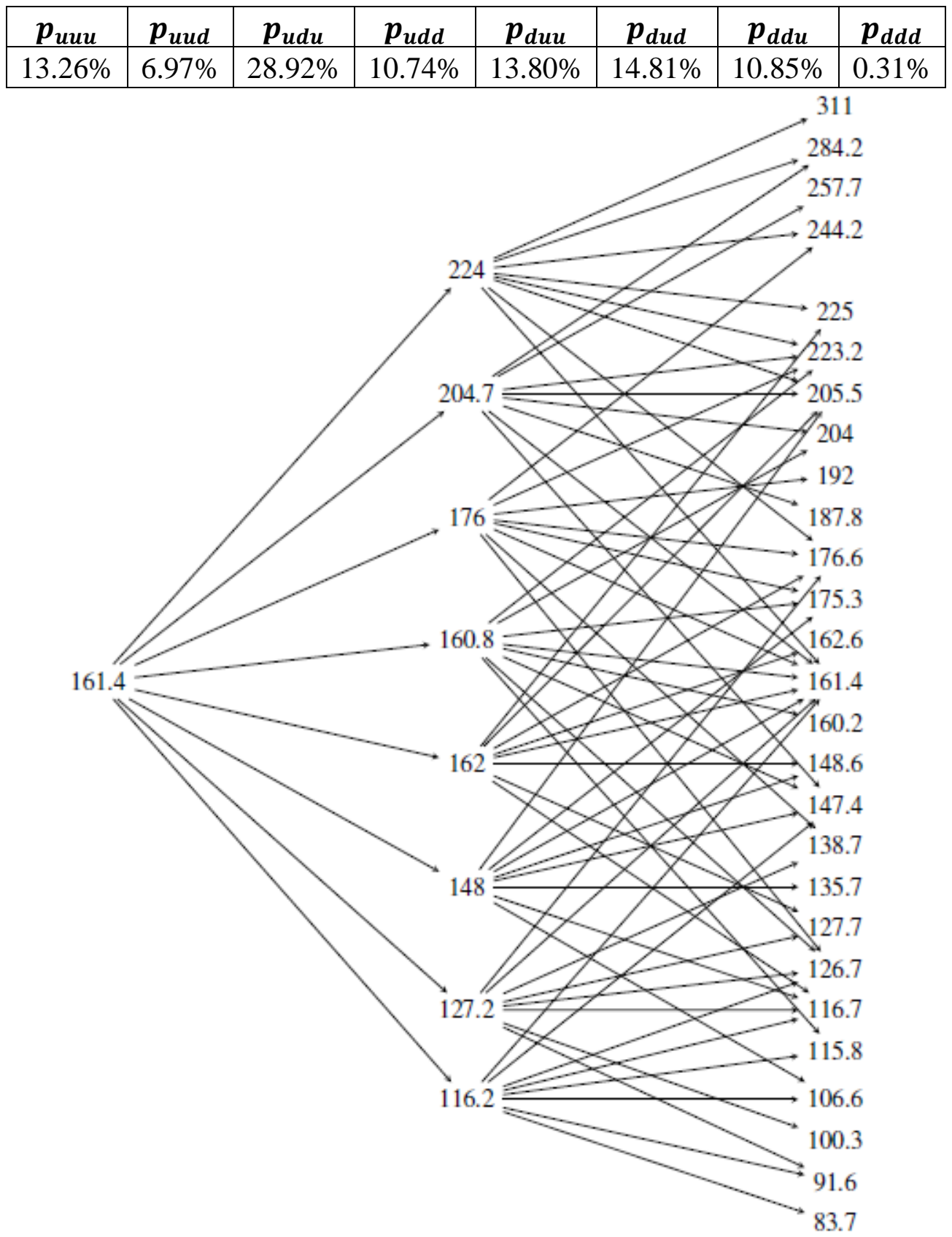

Figure 4. Octanomial Tree for the project value

Based on the state probabilities, the total value is calculated by multiplying the payoffs by these probabilities and discounting the result at the risk-free rate $(2.57 \%)$ as follows

$$
E V=e^{-r \Delta t}\left(\sum_{i=1}^{k} p_{m} \max \left(V_{t, m}-I, 0\right)\right)
$$

where $V_{t, m}$ is the project value without flexibility in time $t$ in each state $m$, and $I$ is the total investment of the gold mine project. Applying equation (8), the project value with flexibility is obtained $(\mathrm{EV}=\$ 146.1)$. This means that the value that the rainbow option adds is $\mathrm{RO}=\$ 82.23$. 


\section{Conclusions}

This paper attempts to present a method for the valuation of a gold mine in Australia under the ROA but incorporating not only one or two sources of uncertainty but three of them. It is possible to conclude that the octanomial model is a suitable and applicable technique for

forecasting three uncertainties in mining projects based on the following ideas:

- If the diffusion term of each GBM maintains constant, the octanomial model will be a recombining tree. This particularity is also present in both the binomial and quadranomial models.

- The parameters obtained by using quarterly information of the gold spot price, USD/AUD exchange rate and IPP for Australia gold mining sector do not produce negative probabilities.

\section{References}

Abdel-Sabour, S., \& Poulin, R. (2006). Valuing real capital investments using the least-squares Monte Carlo method. The Engineering Economist, 51(2), 141-160. https://doi.org/10.1080/00137910600705210

Black, F., \& Scholes, M. (1973). The pricing of options and corporate liabilities. Journal of Political Economy, 81(3), 637-659. https://doi.org/10.1086/260062

Boyle, P. (1988). A Lattice Framework for Option Pricing with Two State Variables. Journal of Financial and Quantitative Analysis, 23(1), 1-12. https://doi.org/10.2307/2331019

Boyle, P., Evnine, J., \& Gibbs, S. (1989). Numerical Evaluation of Multivariate Contingent Claims. The Review of Financial Studies, 2(2), 241-250. https://doi.org/10.1093/rfs/2.2.241

Brennan, M., \& Schwartz, E. (1985). Evaluating natural resource investments. Journal of Business, 58(2), 135-157. https://doi.org/10.1086/296288

Brennan, M., \& Trigeorgis, L. (2000). Project Flexibility, Agency and Competition: New Developments in the Theory and Application of Real Options. In: Brennan, Trigeorgis (Eds.), Oxford University Press, New York.

Clewlow, L., \& Strickland, C. (1998). Implementing Derivatives Models. John Wiley \& Sons, Chichester, UK.

Copeland, T., \& Antikarov, V. (2001). Real Options: A Practitioner's Guide. New York: Texere Publishing Ltd.

Copeland, T., \& Tufano, P. (2004). A Real World Way to Manage Real Options. Havard Business Review, 1-12.

Cortazar, G., Schwartz, E., \& Casassus, J. (2001). Optimal exploration investments under price and geological-technical uncertainty: a real options model. $R \& D$ Management, 31(2), 181-189. https://doi.org/10.1111/1467-9310.00208

Costa-Lima, G., \& Suslick, S. (2006). Estimating the volatility of mining projects considering 
price and operating cost uncertainties. Resources Policy, 31(2), 86-94.

https://doi.org/10.1016/j.resourpol.2006.07.002

Cox, J., Ross, S., \& Rubinstein, M. (1979). Option pricing: A simplified approach. Journal of Financial Economics, 7(3), 229-263. https://doi.org/10.1016/0304-405X(79)90015-1

Dehghani, H., Ataee-pour, M., \& Esfahanipour, A. (2014). Evaluation of the mining projects under economic uncertainties using multidimensional binomial tree. Resources Policy, 39, 124-133. https://doi.org/10.1016/j.resourpol.2014.01.003

Dimitrakopoulos, R., \& Sabour, S. (2007). Evaluating mine plans under uncertainty: Can the real options make a difference?. Resources Policy, 32(3), 116-125.

https://doi.org/10.1016/j.resourpol.2007.06.003

Dixit A. (1989). Entry and exit decisions under uncertainty. Journal of Political Economy, 97, 620-638. https://doi.org/10.1086/261619

Dixit, A., \& Pindyck, R. (1994). Investment under Uncertainty. New Jersey: Princeton University Press.

Gamba, A., \& Trigeorgis, L. (2007). An Improved Binomial Lattice Method for Multi-Dimensional Options. Applied Mathematical Finance, 14(5), 453-475.

https://doi.org/10.1080/13504860701532237

Gibson, R., \& Schwartz, E. (1990). Stochastic convenience yield and the pricing of oil contingent claims. The Journal of Finance, 45(3), 959-976.

https://doi.org/10.1111/j.1540-6261.1990.tb05114.x

Herath, H., \& Kumar, P. (2006). Multinomial Approximating Models for Options. Advances in Investment Analysis and Portfolio Management, 2, 199-226.

Haque, M., Topal, E., \& Lilford, E. (2014). A numerical study for a mining project using real options valuation under commodity price uncertainty. Resources Policy, 39, 115-123.

https://doi.org/10.1016/j.resourpol.2013.12.004

Hillman, T., Zhang, N., \& Jin, Z. (2018). Real-option valuation in a finite-time, incomplete market with jump diffusion and investor-utility inflation. Risks, 6(2), 51.

https://doi.org/10.3390/risks6020051

Kamrad, B., \& Ritchken, P. (1991). Multinomial Approximating Model for Options with k-State Variables. Management Science, 37(12), 1640-1652.

https://doi.org/10.1287/mnsc.37.12.1640

Kelly, S. (1998). A binomial lattice approach for valuing a mining property IPO. Quart. Review Economics and Finance, 38, 693-709.

https://doi.org/10.1016/S1062-9769(99)80097-0

Miranda, O., \& Brandao, L (2013). A Real Option Model to Value an Exploration Mining Project: An Application. Rio de Janeiro: Pontificia Universidade Catolica do Rio de Janeiro. 


\section{Macrothink}

Business and Economic Research

ISSN 2162-4860

2019, Vol. 9, No. 3

Merton, R. (1973). The theory of rational option pricing. The Bell Journal of Economics and Management Science, 4(1), 141-183. https://doi.org/10.2307/3003143

Paddock, J., Siegel, D., \& Smith, J. (1988). Option valuation of claims on real assets: the case of offshore petroleum leases. The Quarterly Journal of Economics, 103(3), 479-508. https://doi.org/10.2307/1885541

Pindyck R. (1993). Investment of uncertain cost. Journal of Financial Economics, 34(1), 53-76. https://doi.org/10.1016/0304-405X(93)90040-I

Schwartz, E., \& Smith, J. (2000). Short-term variations and long-term dynamics in commodity prices. Management Science, 46(7), 893-911.

https://doi.org/10.1287/mnsc.46.7.893.12034

Schwartz, E., \& Trigeorgis, L. (2004). Real options and investment under uncertainty: classical readings and recent contributions, (Eds.). Cambridge: MIT press.

Smith, J., \& MCcardle, K. (1999). Options in the real world: lessons learned in evaluating oil and gas investments. Operational Resources, 47(1), 1-15. https://doi.org/10.1287/opre.47.1.1

Smith, J., \& Nau, R. (1995). Valuing risky projects: Option pricing theory and decision analysis. Management Science, 14(5), 795-816. https://doi.org/10.1287/mnsc.41.5.795

Song, N., Xie, Y., Ching, W., \& Siu, T. (2017). A real option approach for investment opportunity valuation. Journal of Industrial \& Management Optimization, 13(3), 1213-1235. https://doi.org/10.3934/jimo.2016069

Topal, E. (2008). Evaluation of a mining project using discounted cash flow analysis, decision tree analysis, Monte Carlo simulation and real options using an example. International Journal Mining and Mineral Engineering, 1(1), 62-76.

https://doi.org/10.1504/IJMME.2008.020457

Trigeorgis, L. (1996). Real Options: Managerial Flexibility and Strategy in Resource Allocation. Cambridge, Massachusetts: The MIT Press.

Xiao, C., \& Zhou, J. (2017). Pricing mining concessions based on combined multinomial pricing model. Discrete Dynamics in Nature and Society, 2017.

https://doi.org/10.1155/2017/2196702

\section{Copyright Disclaimer}

Copyright for this article is retained by the author(s), with first publication rights granted to the journal.

This is an open-access article distributed under the terms and conditions of the Creative Commons Attribution license (http://creativecommons.org/licenses/by/3.0/). 